\title{
Study on Streptococcus agalactiae infection in Javanese medaka (Oryzias javanicus Bleeker, 1854) model.
}

\begin{abstract}
This study determines the median lethal dose, and describes the clinico-pathological changes and disease development following Streptococcus agalactiae infection in Javanese medaka model. Javanese medakas were infected with S. agalactiae via intraperitoneal (IP) from $10^{4}$ to $108 \mathrm{CFU} / \mathrm{mL}$, and immersion (IM) route from $10^{3}$ to $10^{7} \mathrm{CFU} / \mathrm{mL}$. The $\mathrm{LD}_{5} 0-_{24} 0 \mathrm{~h}$ and clinicopathological changes of the fish was determined until ${ }_{24} 0 \mathrm{~h}$ post infection (hpi). Next, the disease development was determined for $96 \mathrm{hpi}$ in the fish following IP and IM infection at $10^{3} \mathrm{CFU} / \mathrm{mL}$ and $10^{4} \mathrm{CFU} / \mathrm{mL}$, respectively. The $\mathrm{LD}_{5} 0{ }_{24} 0 \mathrm{~h}$ of S. agalactiae in Javanese medaka was lower following IP injection $(4.5 \times 102 \mathrm{CFU} / \mathrm{mL})$, compared to IM route $\left(3.5 \times 10^{3} \mathrm{CFU} / \mathrm{mL}\right)$. The clinical signs included separating from the schooling group, swimming at the surface of water column, lethargy, erratic swimming pattern, corneal opacity and exophthalmia. Histopathological examinations revealed generalized congestion in almost all internal organs, particularly in liver and brain, while the kidney displayed tubular necrosis. Both IP and IM routes showed significant positive correlation $(\mathrm{p}<0.05)$ between the $\mathrm{CFU} / \mathrm{g}$ of $\mathrm{S}$. agalactiae in the fish tissue and fish deaths. Moreover, the lesions for histopathological scoring in selected organs following IP and IM challenges were also reflecting the $\mathrm{CFU} / \mathrm{g}$ and fish deaths. This study indicates the capability of Javanese medaka as a model organism in study of streptococcosis development.
\end{abstract}

Keyword : Javanese medaka; Pathogenesis; Streptococcus agalactiae; Test organism. 